\title{
The Influence of Meteorological Conditions on Atmospheric Pollution in Georgia
}

\author{
Lamzira Lagidze $^{1}$, Lia Matchavariani ${ }^{2}$, David Kereselidze ${ }^{3}$, Nodar Tsivtsivadze ${ }^{3}$, Nino Paichadze ${ }^{4}$, \\ Nargiz Motsonelidze ${ }^{3}$, Maia Vakhtangishvili ${ }^{5}$
}

${ }^{1}$ Dept. of Nature Use Management, Ivane Javakhishvili Tbilisi State University, Tbilisi, Georgia

${ }^{2}$ Dept. of Soil Geography, Ivane Javakhishvili Tbilisi State University, Tbilisi, Georgia

${ }^{3}$ Dept. of Hydro-Meteorology, Ivane Javakhishvili Tbilisi State University, Tbilisi, Georgia

${ }^{4}$ Dept. of Regional Geography, Ivane Javakhishvili Tbilisi State University, Tbilisi, Georgia

${ }^{5}$ Dept. of Geography, Ivane Javakhishvili Tbilisi State University, Tbilisi, Georgia

\section{Email address:}

lagidze_1@rocketmail.com (L. Lagidze), lia.matchavariani@tsu.ge (L. Matchavariani), davitkereselidze@yahoo.com (D. Kereselidze), nluka1@yahoo.com (N. Tsivtsivadze), nana.paichadze@yahoo.com (N. Paichadze), nargiz.motsonelidze@tsu.ge (N. Motsonelidze), maia.vakhtangishvili@tsu.ge (M. Vakhtangishvili)

\section{To cite this article:}

Lamzira Lagidze, Lia Matchavariani, David Kereselidze, Nodar Tsivtsivadze, Nino Paichadze, Nargiz Motsonelidze, Maia Vakhtangishvili. The Influence of Meteorological Conditions on Atmospheric Pollution in Georgia. American Journal of Environmental Protection. Special Issue: Applied Ecology: Problems, Innovations. Vol. 4, No. 3-1, 2015, pp. 67-71. doi: 10.11648/j.ajep.s.2015040301.21

\begin{abstract}
The atmosphere, which is one of the main components of the environment, undergone significant changes in recent decades as a result of anthropogenic impact. The rapid pace of technological processes will significantly increase the anthropogenic load on the environment, which leads to climate change and influence on mankind and ecosystems. The article deals with the dynamics of the aerosols and harmful substance's emissions, described by regions and cities of Georgia over the 2001-2010 year period. The dynamics of "Greenhouse Gas" emissions distributed from the transport sector are evaluated separately (apart). By 2010, the industrial emissions of harmful substances, induced by the operating plants, located in Georgia, amounted to 30134 thous. tons for the year. Among them: the solid pollutants constitute 3658 thous. tons, the liquids and gases amounted to 26476 thous. tons. The main polluter regions of Georgia are: Imeretia, Qvemo Qartli, Adjaria and some regions of Shida Qartli. This contributes to $89 \%$ of the pollution. The most polluted cities include: Batumi, Tbilisi, Gardabani, Rustavi and Kaspi that contributes to $69 \%$ of aerosol emission. The most pollutant sources in Georgia include: transportation (44.4\%), agriculture (27.4\%), energy sector (24.3\%) and industry (3.86\%). The influence of meteorological conditions on atmospheric pollution is assessed (both, in warm and cold periods). The correlation exists in meteorological elements and atmospheric pollutant ingredients, also between this ingredient only, that plays an important role in the aerosol accumulation process in the atmosphere. The complex physical-geographical (high mountains, closed valleys, rich water resources) as well as meteorological (synoptic processes, inversion, isothermal) conditions in Georgia facilitate aerosol accumulation in soil, because of which, changes in microclimate are possible.
\end{abstract}

Keywords: Atmosphere, Pollution, Climate, Greenhouse gases, Ecology, Georgia

\section{Introduction}

Rapid development of technogenic means in the past century, despite certain economic progress had a negative impact on climate changes and faced mankind a real threat of global warming-freezing [13].

Change in ecological balance became obvious that is basically caused by anthropogenic factors, intensive growth and development of cities, expansion of globalization processes, deforestation etc. [10]. All above mentioned factors have an impact on component characteristics of thermal balance that manifests in different forms of disturbance of ecological balance [9].

Over the course of centuries, climate remarkably changes under the influence of anthropogenic factors that have an impact on the whole ecosystem and humans [10]. Proceeding from this fact, reduction of the climate change risks, causing factors and drastic consequences induced by disastrous 
processes are critical.

Due to intensifying of globalization processes and growth trends in industry, agriculture, transport and population, global changes of environment and social field become more and more obvious. These changes are especially clearly revealed in developing countries such as Georgia [11].

The human and climate problem is major for Georgia that is primarily caused by complicated physicalgeographical and meteorological conditions of Georgia, due to which the country is considered as an example of mountain country with diverse climate conditions [3, 4].

Qualitative and quantitative assessment of atmospheric pollution, qualitative state of atmospheric air, establishing a relationship between pollutant ingredients and meteorological conditions, study of atmospheric pollution level and its effect on the environment under conditions of mountainous relief of Georgia are considered among one of the topical problems $[5,7]$.

Research goal: determination of anthropogenic origin greenhouse gas emission stationery sources on Georgian territory by the regions and cities. Namely: determination of basic stationary sources of emission of green house gases of anthropogenic origin at the territory of Georgia according to regions and cities; assessment of dynamics of emission of "green house gases" from transport sector (in Gigagram of $\mathrm{CO} 2$ equivalent), establishment of dynamics of change in aerosols of anthropogenic origin in the atmosphere, of their time-spatial distribution and effect of meteorological conditions (wind, cloudiness, humidity, temperature) on distribution and concentration of aerosols under complicated aerographical and climate conditions of Georgia.

\section{Materials and Methods}

Complicated physical-geographical and climate conditions are characteristic for Georgia. Despite the small area of its territory $(69,7$ thous. sq $\mathrm{km})$, the height difference is more than $5000 \mathrm{~m}$ that causes diversity of climate zones, starting with wet subtropical climate and including zone of perennial ice cover.

Material of observations made by National agency for environmental protection and Department of statistics is used for research.

In order to assess meteoelements' influence on atmospheric pollution, first, periods of considerable atmospheric pollution were discovered, while afterwards we determined correlation dependence between the degree of air pollution and meteorological parameters.

Data processing is based on the method of multifactorial statistical analysis [12].

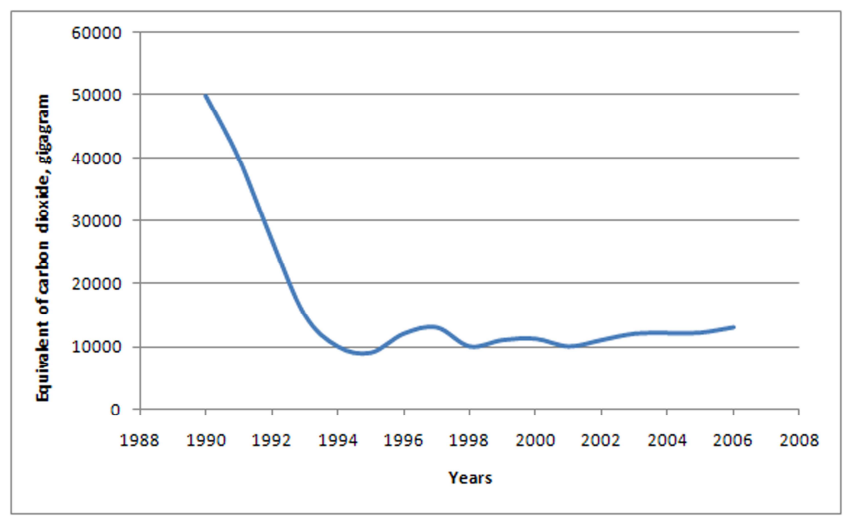

Figure 1. Greenhouse gas emission trends in 1990-2006.

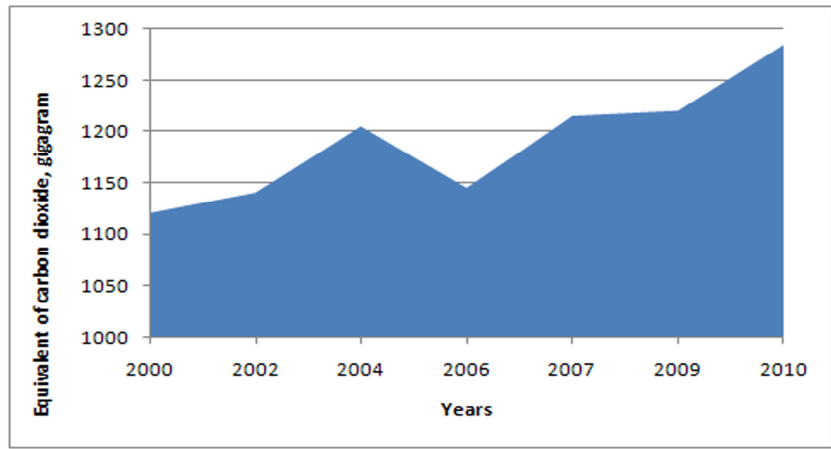

Figure 3. Dynamics of emission of greenhouse gases (Gigagram of $\mathrm{CO}_{2}$ equivalent) from transport sector.

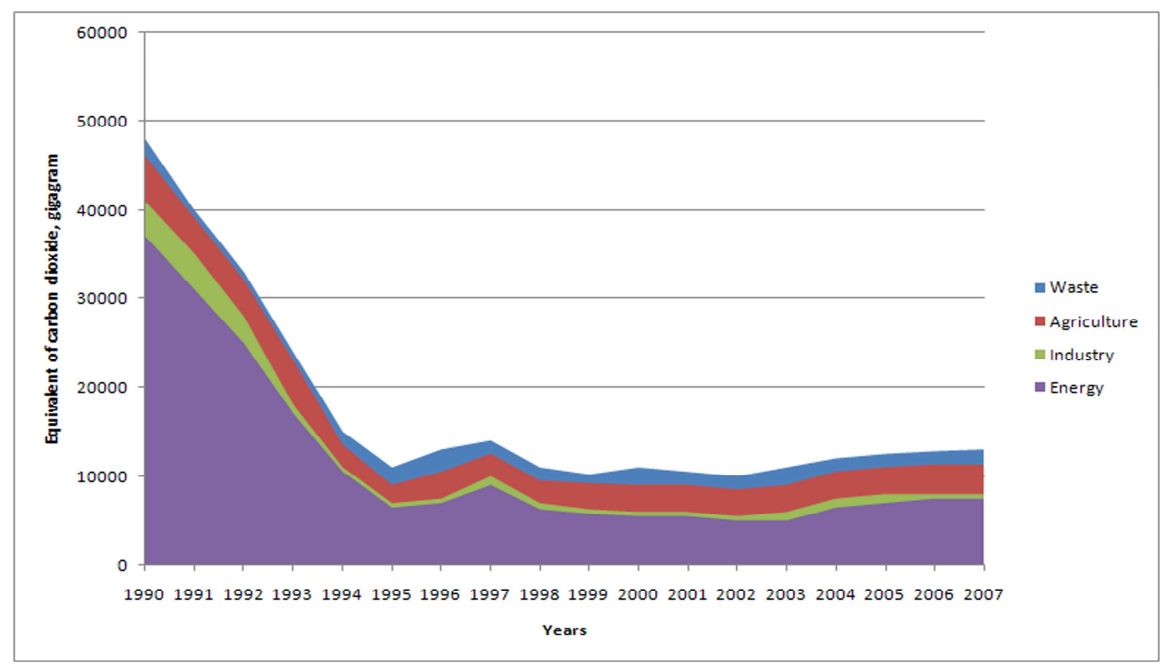

Figure 2. Greenhouse gases emission in 1990-2007 according to sectors. 


\section{Results and Discussions}

Emission of "green house gases" was drastically reduced in Georgia at the end of the 20th century that was caused by political tempest and economic collapse. Especially the substantial effect was caused by energy crisis due to which fossil fuel consumption was considerably reduced and development of industry was inhibited, and as a result, emission of "green house gases" was drastically reduced in Georgia compared with the level of 1990. Despite revival and certain economic recovery (after 2003) emission of "green house gases" hasn't reached mentioned level yet (fig. 1). Greenhouse gas emission trends in 1990-2006 is given in fig. 1.

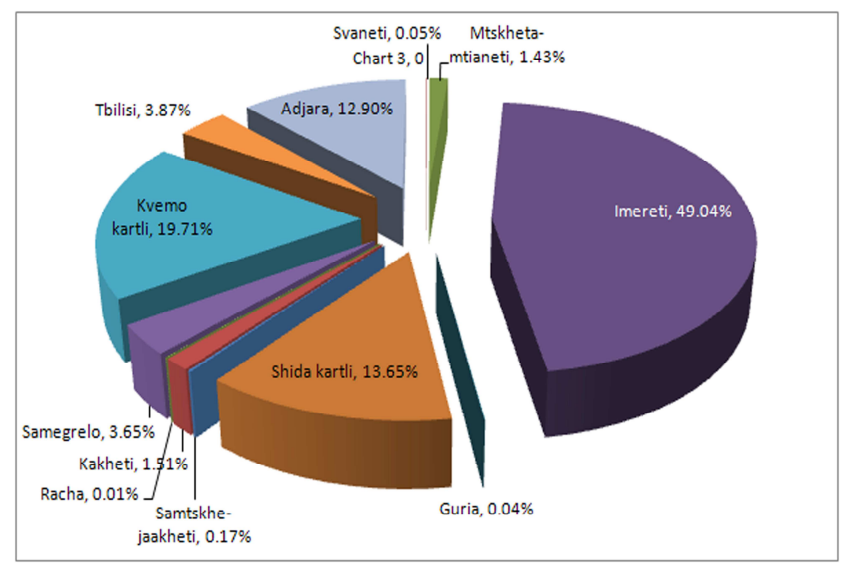

Figure 4. Percentage assessment of aerosol content in the atmosphere, according to regions.

Starting with 90's of the past century, dynamics of atmospheric air pollution are characterized by instability. In 1990-92, temporary improvement of qualitative state of atmospheric air took place under conditions of fuel deficit [6]. Since 1995, due to revival of transport sector major part of air pollution falls on automobile transport, which varies in the range of $80-88 \%$, while after 2001 emissions from the industrial sector, due to partial revival of its potential, were added to the atmospheric air emission from motor vehicles. We should suppose that industrial sector step-by-step will reach a huge scale of development.
A considerable share of air pollution belongs to the energy sector, agriculture and waste. Energy sector involves the whole range of fossil fuel consumption, including transport, while waste sector consists of waste dump and sewage waters, from which greenhouse gases are formed.

On the Fig. 2 basic sources of emission of greenhouse gases in 1990-2007 are represented according to sectors (energy sector, agriculture, waste).

As it can be observed from the drawing, energy sector, similar to all countries worldwide is a leading field in terms of greenhouse gas emissions. Despite considerable reduction, which took place in this field after political cataclysms of 1990 's, energy sector in Georgia is currently on the rise and therefore the emission of greenhouse gases manifests growth trends. The transport sub-sector is especially a great source of emissions in the sector.

Dynamics of emission of greenhouse gases (Gigagram of $\mathrm{CO}_{2}$ equivalent) from the transport sector in 2000-2010 is separately assessed (fig. 3).

Percentage assessment of aerosols in atmospheric air, according to regions and cities is also important (fig.4, fig.5). As it is seen from the diagram, pollution is largest in the Imereti region $(49,0 \%)$, and smallest in Svaneti $(0,05 \%)$, that is due to the different number of enterprises in each region.

Dynamics of change in harmful substance emission (exhaust) in atmospheric air during 2001-2010 according to regions and cities is represented in tables 1,2 .

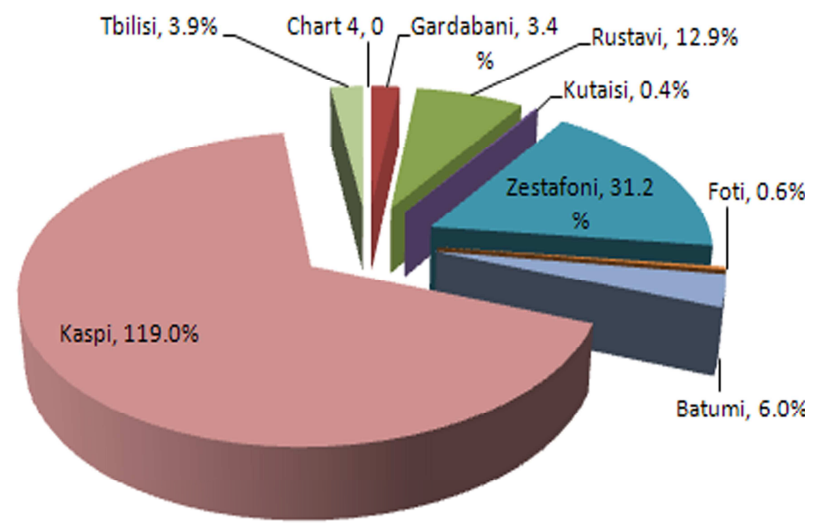

Figure 5. Percentage assessment of aerosol content in the atmosphere, according to cities.

Table 1. Dynamics of change in harmful substance emission in atmospheric air during 2001-2010 according to regions (thou.tons/year).

\begin{tabular}{|c|c|c|c|c|c|c|c|c|c|c|}
\hline \multirow{2}{*}{ Region } & \multicolumn{10}{|c|}{ The amount of harmful emitted substances, tons/year } \\
\hline & 2001 & 2002 & 2003 & 2004 & 2005 & 2006 & 2007 & 2008 & 2009 & 2010 \\
\hline Shida Kartli & 374 & 1825 & 2871 & 3451 & 3063 & 3748 & 1836 & 1351 & 2718 & 4112 \\
\hline Kvemo Kartli & 7522 & 5339 & 5193 & 5786 & 5502 & 7479 & 6485 & 5007 & 4174 & 5939 \\
\hline Tbilisi & 697 & 255 & 188 & 317 & 342 & 304 & 200 & 159 & 163 & 1166 \\
\hline Samegrelo-Zemo Svaneti & 74 & 113 & 40 & 29 & 754 & 658 & 1645 & 964 & 565 & 1099 \\
\hline Samckhe-Kavakheti & 40 & 62 & 149 & 227 & 152 & 192 & 128 & 486 & 147 & 51 \\
\hline Kakheti & 108 & 6 & 430 & 79 & 42 & 110 & 80 & 184 & 839 & 455 \\
\hline Adjara & 4425 & 5452 & 3680 & 2934 & 4529 & 4429 & 4676 & 4034 & 2738 & 2074 \\
\hline Kvemo Svaneti-Lechkhumi & 10 & 17 & 8 & 43 & 135 & 67 & 42 & 55 & 47 & 14 \\
\hline Imereti & 482 & 464 & 3629 & 6979 & 8985 & 9880 & 11089 & 12070 & 9160 & 14776 \\
\hline Mtskheta-Mtianeti & 381 & 541 & 566 & 554 & 515 & 523 & 972 & 925 & 348 & 431 \\
\hline
\end{tabular}




\begin{tabular}{lllllllllll}
\hline \multirow{2}{*}{ Region } & \multicolumn{1}{l}{ The amount of harmful emitted substances, tons/year } \\
\cline { 2 - 8 } & $\mathbf{2 0 0 1}$ & $\mathbf{2 0 0 2}$ & $\mathbf{2 0 0 3}$ & $\mathbf{2 0 0 4}$ & $\mathbf{2 0 0 5}$ & $\mathbf{2 0 0 6}$ & $\mathbf{2 0 0 7}$ & $\mathbf{2 0 0 8}$ & $\mathbf{2 0 0 9}$ & $\mathbf{2 0 1 0}$ \\
\hline Guria & 26 & 28 & 22 & 20 & 224 & 150 & 120 & 245 & 141 & 11 \\
Sum & 14186 & 14119 & 16779 & 20583 & 24289 & 27584 & 27300 & 25513 & 21139 & 30134 \\
\hline
\end{tabular}

Table 2. Dynamics of change in harmful substance emission in atmospheric air during 2001-2010 according to cities (thous. tons/year).

\begin{tabular}{|c|c|c|c|c|c|c|c|c|c|c|}
\hline \multirow{2}{*}{ Cities } & \multicolumn{10}{|c|}{ Amount of harmful emitted substances, tons/year } \\
\hline & 2001 & 2002 & 2003 & 2004 & 2005 & 2006 & 2007 & 2008 & 2009 & 2010 \\
\hline Tbilisi & 697 & 255 & 188 & 322 & 342 & 304 & 200 & 159 & 163 & 1166 \\
\hline Batumi & 4379 & 5365 & 3618 & 2815 & 4409 & 4175 & 4517 & 3783 & 2588 & 1818 \\
\hline Kutaisi & 69 & 46 & 66 & 41 & 59 & 69 & 172 & 72 & 230 & 118 \\
\hline Rustavi & 2900 & 3510 & 3442 & 3348 & 2614 & 3174 & 3289 & 2058 & 1885 & 3875 \\
\hline Zestafoni & 209 & 174 & 3097 & 6722 & 8563 & 8480 & 8742 & 8315 & 5517 & 9387 \\
\hline Gardabani & 4940 & 1273 & 967 & 1678 & 2186 & 3603 & 2625 & 2521 & 1548 & 1038 \\
\hline Kaspi & 308 & 1622 & 2738 & 3307 & 2714 & 3401 & 1474 & 1089 & 2270 & 3584 \\
\hline Sum & 14068 & 12734 & 14380 & 18592 & 20887 & 23635 & 21402 & 18353 & 14356 & 21175 \\
\hline
\end{tabular}

The amount of harmful substances (thousand tons/year) emitted in atmospheric air by automobile transport in 2010 is given in Table 3. Lead emission rate from gasoline consumption cannot be calculated in mentioned table due to unavailability of data on gasoline quantity.

Table 3. The amount of harmful substances emitted in atmospheric air by automobile transport in 2010 (thousand tons/year).

\begin{tabular}{|c|c|c|c|}
\hline \multirow[b]{2}{*}{ Harmful substances } & \multirow[b]{2}{*}{ Sum } & \multicolumn{2}{|l|}{ Among them } \\
\hline & & $\begin{array}{l}\text { Petrol } \\
\text { Consumption }\end{array}$ & $\begin{array}{l}\text { Diesel Fuel } \\
\text { Consumption }\end{array}$ \\
\hline Carbon monoxide & 243.852 & 191.942 & 51.910 \\
\hline Nitrogen dioxide & 25.441 & 10.906 & 14.535 \\
\hline Sulfurous anhydride & 9.178 & 0.872 & 8.306 \\
\hline Hydrocarbons & 57.739 & 34.899 & 22.840 \\
\hline Soot & 6.491 & 0.262 & 6.229 \\
\hline Benzo (a) piret & 0.000229 & 0.0001003 & 0.0001287 \\
\hline Sum & 342.701 & 238.881 & 103.820 \\
\hline
\end{tabular}

The total amount of harmful substances emitted in 2010 in atmospheric air from operating industries situated on the territory of Georgia equals to 30,134 thous. tons annually, among them solid substances count 3,658 thous. tons, while gaseous and liquid - 26,476 thous. tons. Imereti, Kvemo Kartli, Adjara and Shida Kartli regions are among main pollutants of atmospheric air in Georgia, since $89 \%$ of total emissions fall on them in Georgia. Zestafoni, Batumi, Tbilisi, Gardabani, Rustavi and Kaspi are the main cities - pollutants of atmospheric air, and roughly $69 \%$ of total emissions in Georgia fall on them.

Leading role of transport sector in atmospheric air pollution is also determined by results of comparative analysis of emission amounts into the atmosphere of harmful substances detrimental to human health, according to which automobile transport $(44,4 \%)$, agriculture $(27,43 \%)$, energy $(24,28 \%)$, industry $(3,86 \%)$ are the basic sources of atmospheric pollution [8]. Meteorological processes have a significant effect on time-spatial distribution of aerosols [8].

Change in wind direction and velocity, air temperature, state of the atmosphere, precipitations, humidity, water steam elasticity and few clouds were selected as predictors of correlation relationship.

Analysis of correlation relationship between polluting ingredients and microelements showed that gaseous pollutants are in correlation to each other that is a result of phytochemical activity of these ingredients. Their interaction in warm periods is stronger than in cold periods.

The correlation relationship of polluting ingredients is represented as follows:

- Dust is not in correlation relationship with $\mathrm{SO}_{2}, \mathrm{CO}$ and $\mathrm{NO}_{2}$, since sources of generation of these gases are different;

- Dust and $\mathrm{SO}_{2}$ are washed off by precipitations, that is characteristic for all seasons. Snow cleans the atmosphere from harmful admixtures more, than rain.

- $\mathrm{CO}$ and $\mathrm{NNO}_{2}$ are not washed off by precipitations due to their physical-chemical peculiarities.

- $\mathrm{SO}_{2}$ and $\mathrm{NO}_{2}$ are in correlation dependence on temperature. Positive correlation relationship $(0,65 ; 0,67)$ of these elements with temperature is revealed that is manifested in the greenhouse effect.

- In cold period $\mathrm{CO}$ is in negative correlation with temperature that is caused by increase in ground inversion capacity due to decrease of temperature near Earth's surface.

- CO concentration is in close relation with ground inversion (correlation coefficient is 0,69 ).

- In cold seasons positive correlation relationship between $\mathrm{CO}$ and temperature is revealed, that is the result of the presence of greenhouse gas effect.

- All ingredients of pollution are in negative correlation with relative humidity that is explained by the hydrolysis ability of these ingredients.

- Concentration of ground ozone is in negative correlation with the dust concentration $(0,39 \pm 0,02)$, since the dust content in the cities reduces ultraviolet radiation and impedes phytochemical formation of ozone.

- In cold seasons ozone is in negative correlation with $\mathrm{NO}_{2}$ $(0,4 \pm 0,02)$ that is explained by ozone disintegration due to high levels of pollution, short duration of sunshine and low temperature.

- In warm seasons ozone is in positive correlation with $\mathrm{NO}_{2}$, since phytochemical pollution is depended on radiation and temperature.

Availability of different kinds of aerosols in the atmosphere (industrial dust, nitrogen and sulfur compounds, soot, cement, 
etc.), the quantity of which is above MAC are observed in industrial cities. All this is caused both by the presence of local sources and diverse meteorological processes, which are characteristic for Georgia and by complicated orographic and climate conditions. Mentioned admixtures cause contraction and complications of the disease that is promoted by various climate-ecological factors, air temperature, humidity, atmospheric pressure, inversion, isothermy, synoptical processes etc.

Such decision is substantiated by the circumstance that atmosphere of Georgian cities is severely polluted that is promoted by complicated physical-geographical position of Georgia (high mountains, closed gorges, abundant water resources) and meteorological-climatic conditions due to which microclimate changes are expected.

\section{Conclusions}

- Ecological state of the atmosphere is depended on the specificity and intensity of pollution source, physical-geographic and meteorological conditions and on the level of development of national economy and ecological education.

- $92 \%$ of atmospheric pollution on the territory of Georgia fall on automobile transport. Single-use concentration 20-30 times exceeds maximum allowable standards.

- Basic polluting regions of Georgian atmosphere are Imereti, Kvemo Kartli, Adjara and Shida Kartli.

- Unstable meteorological conditions: synoptical processes, light winds, intensive and isomeric stratification impede admixture distribution in higher layers, as a result takes place aerosols accumulation in troposphere.

- Effect of meteorological conditions on atmospheric pollution is established. There is a correlation relationship both between meteorological elements and pollutant ingredients of the atmosphere, as well as between the ingredients which play significant role in the process of aerosol accumulation.

- Despite the global influence of climate changes, intensity and scope of the impact of its numerous manifestations have local specificity, based on the geographical position of different regions and meteorological characteristics.

\section{References}

[1] Amiranashvili A., Bliadze T., Chikhladze V. Photochemical Smog in Tbilisi. Universal, Tbilisi, 2012.

[2] Bhola, R., Gurjar L. T., Molina Chandra and Ojha S.P. Air Pollution (Health and Environmental Impacts). CRC Press, New York, 2010.

[3] Gunia, G. Meteorological aspects of atmosphere ecological monitoring. Georgian Academy of Sciences, Tbilisi, 2005.

[4] Gunia, G., Saralidze R. Pollution of Industrial District in Conditions of Paired Meteorological Parameters. Tbilisi, Caucasian Geographical Review, \#10, 2009, 44-47.

[5] Kharchilava D.F., Tsibadze A.D., Siordia S.I. The complex influence of atmospheric pollution and ground level ozone concentration on growth of different diseases. Tbilisi: proceedings of the Symposium on Modern Problems of Atmospheric Ozone, 1998, 141-146.

[6] Lagidze L., Khidasheli N., Motsonelidze N. Climate-ecological description of Georgian Industrial Cities. Proceedings of Tbilisi University, 322, 1997, 118-123.

[7] Lagidze L., Khidasheli N., Siordia S., Motsonelidze N. Medical assessment of weather in accordance with meteorological, climate and ecological factors. Tbilisi, Caucasian Geographic Journal, v. 5, 2005, 36-39.

[8] Lagidze L., Matchavariani L., Tsivtsivadze N., Paichadze N., Motdpnelidze N., Vakhtangishvili. Medical Aspects of Atmosphere Pollution. Journal of Environmental Biology. Publisher: Triveni Enterprises. ISSN: 0254-8704; eISSN: 2394-0379. Special Issue of JEB, 2015, 36(1), 2015, 101-107.

[9] Main N. Integrated monitoring concentrations and their use in climate monitoring systems projecting. Leningrad: proceedings of the 2nd International Symposium on global integrated monitoring, 1981, 57-61.

[10] Mark Z. Jacobson. Atmospheric Pollution. Cambridge University Press, 2002.

[11] Matchavariani L., Lagidze L. Environment Transformation in Georgia as a result of Climate Change. Cambridge Scholars Publishing Book: Environment and Ecology in the Mediterranean Region, 2012, 379-393.

[12] Kobisheva N., Narovilianski G. Climatological Processing of the Meteorological Information. Gidrometeoizdat, Leningrad, 1978.

[13] World Atlas of Atmospheric Pollution Anthem Press, UK \& USA, 2011. 